San Jose State University

SJSU ScholarWorks

Master's Theses

Master's Theses and Graduate Research

1990

\title{
Habitat utilization by great blue herons (Ardea herodias) in Elkhorn Slough, California
}

Scott Charles Buchanan

San Jose State University

Follow this and additional works at: https://scholarworks.sjsu.edu/etd_theses

\section{Recommended Citation}

Buchanan, Scott Charles, "Habitat utilization by great blue herons (Ardea herodias) in Elkhorn Slough, California" (1990). Master's Theses. 3247.

DOI: https://doi.org/10.31979/etd.7p8e-zhqq

https://scholarworks.sjsu.edu/etd_theses/3247

This Thesis is brought to you for free and open access by the Master's Theses and Graduate Research at SJSU ScholarWorks. It has been accepted for inclusion in Master's Theses by an authorized administrator of SJSU ScholarWorks. For more information, please contact scholarworks@sjsu.edu. 


\section{INFORMATION TO USERS}

The most advanced technology has been used to photograph and reproduce this manuscript from the microfilm master. UMI films the text directly from the original or copy submitted. Thus, some thesis and dissertation copies are in typewriter face, while others may be from any type of computer printer.

The quality of this reproduction is dependent upon the quality of the copy submitted. Broken or indistinct print, colored or poor quality illustrations and photographs, print bleedthrough, substandard margins, and improper alignment can adversely affect reproduction.

In the unlikely event that the author did not send UMI a complete manuscript and there are missing pages, these will be noted. Also, if unauthorized copyright material had to be removed, a note will indicate the deletion.

Oversize materials (e.g., maps, drawings, charts) are reproduced by sectioning the original, beginning at the upper left-hand corner and continuing from left to right in equal sections with small overlaps. Each original is also photographed in one exposure and is included in reduced form at the back of the book.

Photographs included in the original manuscript have been reproduced xerographically in this copy. Higher quality $6 "$ " 9 9" black and white photographic prints are available for any photographs or illustrations appearing in this copy for an additional charge. Contact UMI directly to order.

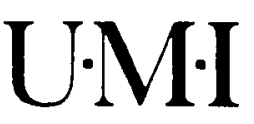




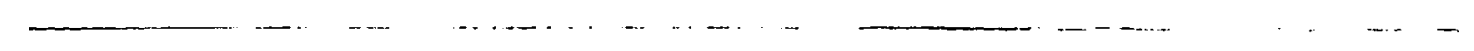


Order Number 1340500

Habitat utilization by great blue herons (Ardea herodias) in Elkhorn Slough, California

Buchanan, Scott Charles, M.S.

San Jose State University, 1990 
- 


\title{
HABITAT UTILIZATION BY GREAT BLUE HERONS (ARDEA HERODIAS) IN ELKHORN SLOUGH, CALIFORNIA
}

\author{
A Thesis \\ Presented to \\ The Faculty of the Department of Biological Sciences \\ San Jose State University
}

In Partial Fulfillment of the

Requirements for the Degree

Master of Science

\author{
by \\ Scott Charles Buchanan \\ May, 1990
}


APPROVED FOR THE DEPARTMENT OF SCIENCE

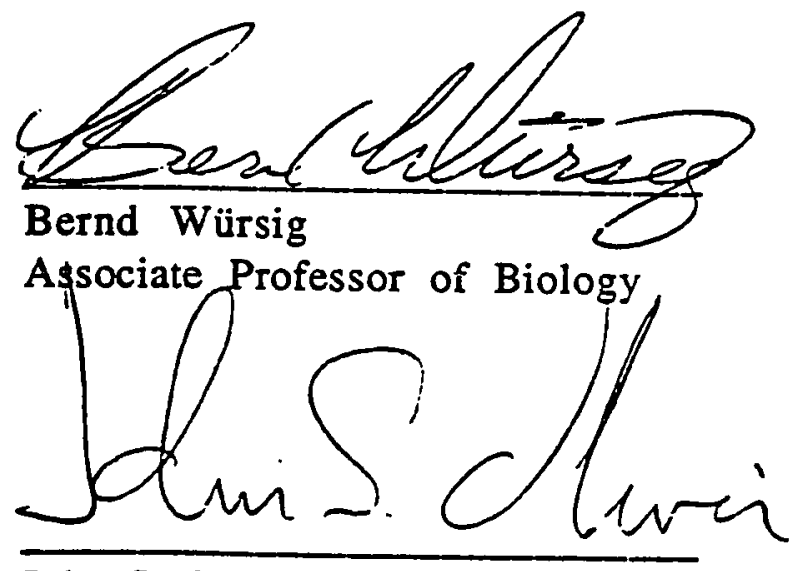

John S. Oliver

Adjunct Associate Professor of Biology

Daniel w. Que..

Dan Anderson

Professor of Wildlife Biology

APPROVED FOR THE UNIVERSITY

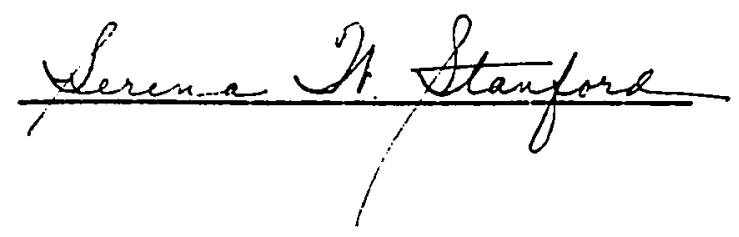




\title{
ABSTRACT \\ HABITAT UTILIZATION BY GREAT BLUE HERONS (ARDEA HERODIAS) IN ELKHORN SLOUGH, CALIFORNIA
}

Scott Charles Buchanan

\begin{abstract}
Observations of individual herons within Elkhorn Slough, California indicated differences in social interactions and foraging strategies within six sub-habitats. There are four primary foraging habitats. Two habitats are mainly used for loafing, preening and social interactions. I hypothesize that these social interactions may involve a hierarchy which is carried into the foraging habitats and occur primarily to increase individual foraging success. Significant differences in foraging behavior within and between habitats existed for both 1986 and 1987. Differences in foraging success and prey size were also significant. The observed foraging success reflects the primary use of each habitat. These results were consistent with the behavioral trends found in the habitats. The effects of weather and tide on foraging success were also assessed. Cloud cover significantly reduced foraging success, while wind and tidal conditions did not affect foraging success. Observations of a newly colonized rookery were made to determine numbers of nesting pairs and nesting success.
\end{abstract}




\section{ACKNOWLEDGEMENTS}

I would like to thank Bernd Würsig, John S. Oliver, and Dan Anderson for serving on my committee. Special thanks to Marc Silberstein for his understanding and encouragement during my time in the field. Further support was provided by the David and Lucile Packard Foundation and the Monterey Chapter of the Audubon Society. I also wish to express my gratitude to my wife and family for their efforts and support. Most especially I thank Bernd Würsig for being my educator and friend. 


\section{TABLE OF CONTENTS}

LIST OF FIGURES......................................................................................................... vi

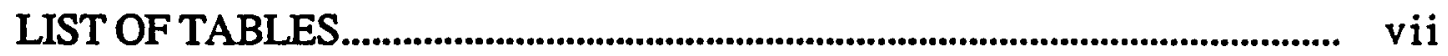

INTRODUCTION............................................................................................... 1

STUDY AREA AND METHODS......................................................................... 4

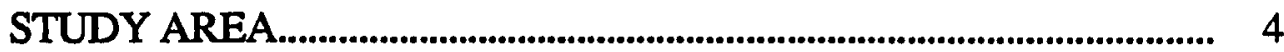

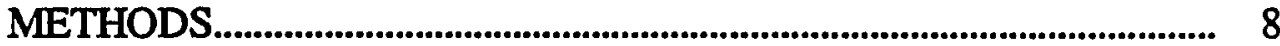

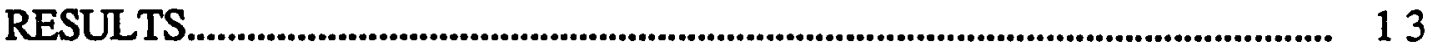

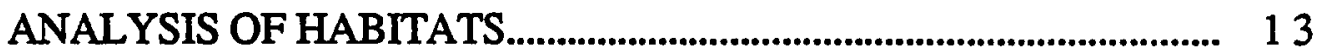

EFFECTS OF WEATHER ON FORAGING................................................ 25

EFFECTS OF TIDE ON FORAGING.................................................... 30

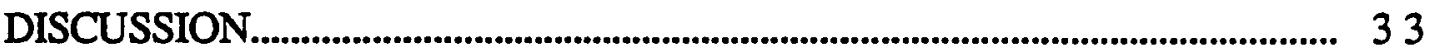

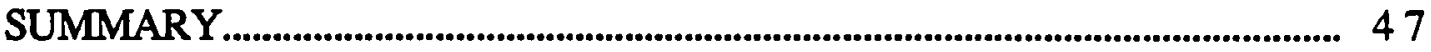

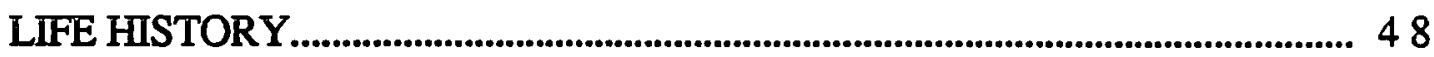

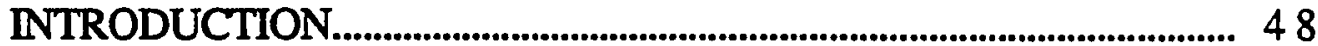

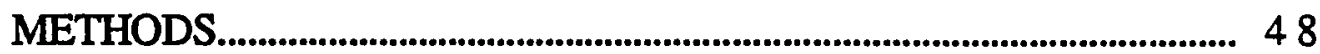

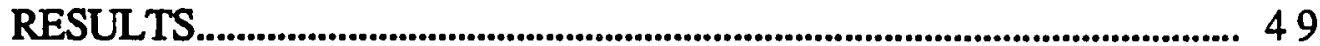

Pre-breeding Behavior............................................................... 49

Nesting Behavior................................................................................ 50

Incubation and Brooding of Young........................................ 51

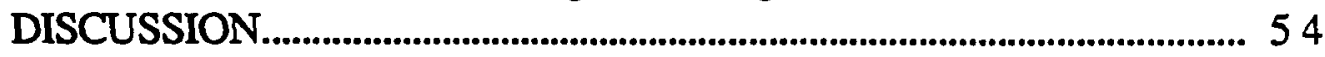

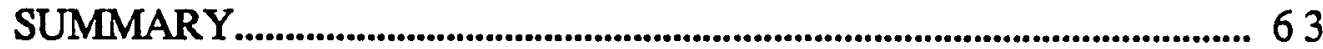

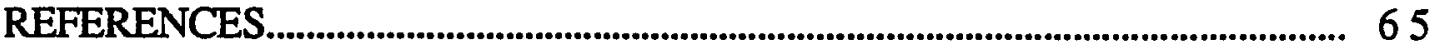

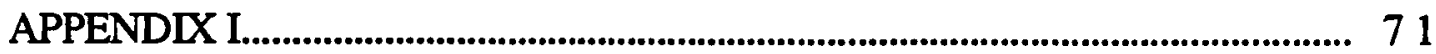




\section{LIST OF FIGURES}

FIGURE 1 Map of Elkhorn Slough.................................................... 5

FIGURE 2 Percent Time of Observed Behaviors - 1986........ 14

FIGURE 3 Percent Time of Observed Behaviors - 1987......... 15

FIGURE 4 Comparisons of Observed Behaviors Within Each Habitat......................................................................... 18

FIGURE 5 Comparisons of Observed Behaviors Between Habitats.................................................................................. 19

FIGURE 6 Map of Nesting Colony From Aerial Photograph Side View................................................................................. 61

FIGURE 7 Map of Nesting Colony from Aerial Photograph Top View................................................................................ 62 


\section{LIST OF TABLES}

TABLE 1 Foraging Success - 1986 and1987........................... 20

TABLE 2 Average Prey Length....................................................... 21

TABLE 3 Effects of Wind on Foraging Success............................ 26

TABLE 4 Effects of Wind on Relative Prey Size........................ 27

TABLE 5 Effects of Cloud Cover on Foraging Success............. 28

TABLE 6 Effects of Cloud Cover on Relative Prey Size......... 29

TABLE 7 Effects of Tidal Height on Foraging Success............ 31

$\begin{array}{llll}\text { TABLE } & 8 & \text { Effects of Tidal Height on Relative Prey Size......... } 32\end{array}$ 


\section{INTRODUCTION}

The Great Blue Heron represents an ideal subject for a habitat utilization study. Large size, standing over one meter, and relatively slow movement of this bird make it easily observable from great distances.

In this study, I examined the foraging behaviors of Great Blue Herons Ardea herodias within several distinct estuarine subhabitats to determine if different foraging strategies and success exist within those habitats. Behavioral patterns of each subhabitat reflects the adaptability of herons to utilize available habitats. Variations in prey, weather, and tidal conditions affect heron behavior and foraging success (Krebs 1974). These patterns and conditions give insight into the overall utilization of Elkhorn Slough by Great Blue Herons.

The question of how and why animals budget their time and utilize their space has been a central theme in behavioral ecology (Schoener 1971, Charnov 1976, Krebs 1978, Krebs et al 1981). 
Although the list of references on foraging optimization is becoming extensive, a discrepancy exists between what animals ought to do in theoretical models and what animals actually do in the field (Erwin 1983, 1985). An increasing number of field studies have begun to address foraging behavior and ecology (Gill and Wolf 1975, 1978, Pyke 1978, Howell and Hartl 1980, Rudolph 1982).

Herons in estuarine habitats are faced with complex feeding situations (Richner 1986). Prey density and habitats are in constant change with the tide. These differences in density, type, distribution and quality of prey all influence what a predator eats. This becomes most interesting, and most difficult to resolve, in mobile, wide ranging animals such as large birds whose selection of prey may be expected to vary from habitat to habitat within a region (Kushlan 1979).

Several studies of feeding behavior (Jenni 1969, Recher and Recher 1969, 1972, Multon 1972, Kushlan 1972, 1976) provide an initial understanding of heron ecology. The role of habitat in determining heron foraging behavior was not addressed in these 
studies. Differences in prey densities, water depth, piant cover and other characteristics of foraging sites may vary, and therefore foraging behaviors and efficiency are likely to vary. These variables in habitat conditions are essential in the ecological analysis of heron behavior (Kushlan 1976).

The estuarine habitat of Elkhorn Slough is a unique system that has been altered through human disturbances, creating a number of sub-habitats. Thus, herons foraging within this system must make a variety of foraging decisions based on physical conditions, prey availability and past experiences. Once a decision to forage in a particular habitat is made, a further choice in foraging strategy is essential to maximize foraging success. 


\section{STUDY AREA AND METHODS}

Study Area

Elkhorn Slough is a large marine estuary covering about 2,500 acres. The slough lies between Santa Cruz and Monterey, California, and empties into Monterey Bay almost directly at the head of the Monterey Submarine Canyon at Moss Landing (Figure 1). The main channel extends almost $7 \mathrm{~km}$. inland and has an axial length of nearly $11 \mathrm{~km}$. (Browning 1972). It averages between $100 \mathrm{~m}$. wide and $5 \mathrm{~m}$. deep at the mouth to roughly $15 \mathrm{~m}$. wide and $1.5 \mathrm{~m}$. deep near Hudson's Landing (Smith 1973).

The slough has been altered many times through human intervention since the 1880's. In 1947, Moss Landing Harbor jetties were constructed, opening the slough to direct tidal action. Recent action in 1983 and 1985 has attempted to restore marsh lands to a semi-natural state (Ken Moore and Marc Silberstein, pers. comm.). The resulting influences have created a unique and diverse environment comprised of several distinct sub-habitats determined by physical and biological parameters. Based on these 


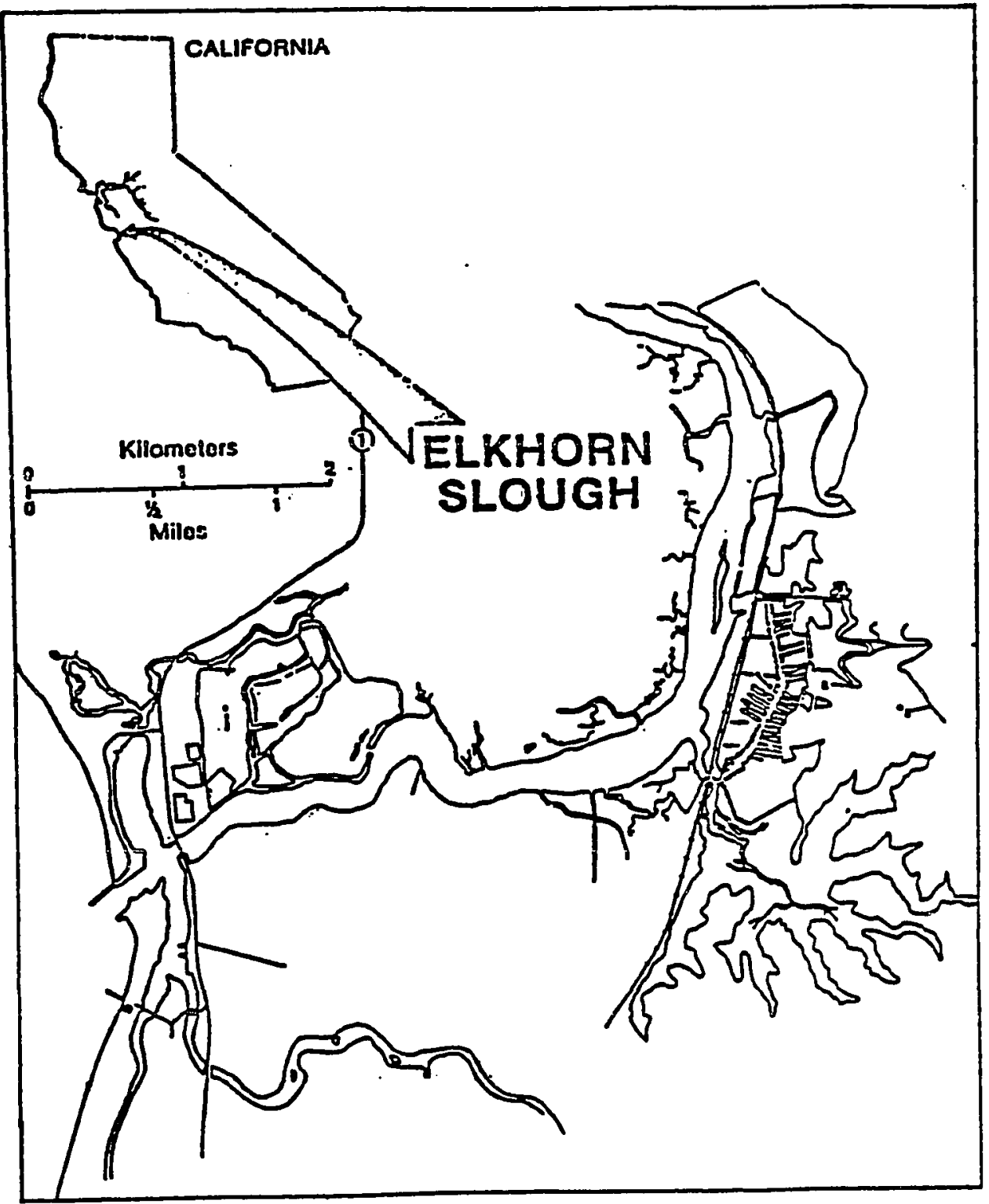

Figure 1. Map of Study Area 
parameters, six sub-habitats were identified:

1) The Salicornia flats habitat is comprised of low lying pickleweed Salicornia pacifica which is entirely exposed at low tides and submerged to varying degrees at high tides. This habitat is transected by an extensive network of tidal channels. The Salicornia flats occur on both banks of the main channel and range in width between $50-200 \mathrm{~m}$. from channel bank to upland slopes.

2) The islands habitat has been altered the most by recent human efforts to restore a wetland habitat. It is an area comprised of many man-made earthen islands and benches with varying heights and therefore varying tidal influences. Low tides expose all of the islands and benches. Extremely low tides expose mud flats in several areas, while high tides totally submerge several of the islands and benches. Sparse coverage of Salicornia and several other salt-tolerant plant species exists on the exposed areas of the islands and benches. The topography of this habitat is the most varied and has the greatest range of physical and biological factors in the six described habitats. 
3) The inland shallows habitat is the shallow banked transition zone between the fluctuating water levels and the muddy shore line of the inner slough. This habitat is comprised of three distinct zones: a vegetated bank above high tide, a gradual mud sloped bank advancing at low tide and retreating at high tide, and the shallow waters of the inner most slough. This habitat is the smallest in area, yet it is found in several locations throughout the study area.

4) The restored marsh is a habitat altered through human intervention. A tide gate was built in 1984 to re-establish a low lying marsh area. A channel was cut through the low lands permitting slough waters to flood the area via the tide gate. The vegetation is dominated by patches of Salicornia which are inundated by a relatively constant depth of water only slightly influenced by tides. This habitat is expansive and is homogeneous in nature.

5) The main channel habitat is strongly influenced by tides. At high tide it is restricted to the steep mud banks typically found at the transition with the Salicornia flats. At low tides the habitat 
extends from these steep eroding banks into the mud shoals and the water of the main channel. Erosion is a strong factor determining the bank condition. Fast flowing tidal waters undercut the banks and accumulate debris forming shallow mud shoals.

6) The mud flat is an expansive habitat characterized by smooth tidal channels and pools exposed at low tides. High tide inundates the area via two main channels and connecting tributaries. There is very little standing vegetation in this habitat, but algal blooms of Entromorpha $\mathbf{s p . ~ c o v e r ~ l a r g e ~ a r e a s ~ s p o r a d i c a l l y ~}$ through the summer and fall months.

\section{Methods}

These habitats can be observed from several vantage points within the ESNES. From these vantage points individual birds were observed from distances of $50 \mathrm{~m}$ to $500 \mathrm{~m}$, with a $20 \mathrm{x}$ spotting scope. Precautions were taken at close range to ensure that my presence did not alarm the observed bird. Observations closer than $100 \mathrm{~m}$ were rare and resulted from careful stalking or, more often, a heron approaching my position. Herons were 
observed by the same observer between 0800 hours and 1800 hours from 16 January to 29 July, 1986 and 1 February to 1 June, 1987 for a total of 5,500 minutes. Since the entire slough is extensive and some areas are inaccessible by foot, observations were concentrated within areas observable from the ESNES. Although all observations occurred from the ESNES, several censuses indicated that at least $25-30$ individual herons frequent the observed area. It was possible through variations in plumages to identify adult, immature, and fledgling birds (Bent 1926). Since foraging efficiency of juvenile herons is lower than adults (Recher and Recher 1969), only adult birds were observed for the comparison of forage and habitat use. The closely related Grey Herons of Europe were found to be territorial foragers (Cook 1978). Efforts were made to obtain data from as many different individuals as possible. This was accomplished by noting locations and movements of all visible herons. Efforts were made to observe as many of the visible herons in as many different habitats as possible.

A Great Blue Heron can capture and swallow a small fish 
within seconds; therefore individuals were kept under constant surveillance during 30 minute observation periods. The habitat type and depth of water (gauged by the water level on the heron's leg) were noted. Also, when foraging, estimated lengths of captured prey (using the bird's beak as a reference) and, when possible, prey species were recorded. Time of day, tidal height, cloud cover, and wind strength were noted as well as each successful and unsuccessful prey strike. Activity was noted at one minute intervals, in an attempt to determine the frequency with which different behaviors and foraging strategies were utilized. These activities were categorized into seven different foraging and non-foraging behaviors based on a list of heron behaviors published by Kushlan (1976).

Hunched Stand - Primarily a non-foraging stance commonly associated with loafing behaviors. A heron holds its head and neck in an "S" curve tight against its upright body.

Upright Stand and Wait - A position epitomized by the Great Blue Heron (Kushlan 1976). This behavior indicates an alert bird foraging or watching for other herons or possible threats. The 
posture is upright with head and neck fully extended away from the body. When foraging, the heron remains motionless except for quick eye and head movements.

Crouched Stand and Wait - A motionless posture characterized by the body being held roughly horizontal to the water surface or ground. The legs are bent while the neck and head are partially retracted. This stance typically occurs prior to a strike.

Walk Slowly Upright - This is a position identical to the Upright Stand and Wait except that the heron moves slowly, stalking prey. Typically less than a step a second occurs during Walk Slowly.

Walk Slowly Crouched - This position is described by Recher and Recher (1972) as a slow stalk. A heron moves slowly, normally less than a step a second, with body held low and nearly horizontal to the substrate with neck partially retracted.

Walk Quickly - A behavior characterized by a heron walking through water or ground cover catching disturbed prey or simply chasing mobile prey. This behavior is different from Walk Slowly, 
since the heron flushes prey rather than stalking, and the posture is less rigid. Also, a heron typically takes several steps per second.

Other behaviors noted include mainly non-foraging activities. Preening was a prevalent non-foraging behavior, as well as flights of varying distances of 10 to 200 meters. Interspecific interactions included being chased and chasing, often covering great distances by air. Confrontation occurring on the ground often included a threatening head up and wing out posture. Intra-specific interactions occurred between herons and both Snowy Egrets Egretta thula and Great Egrets Casmerodius albus. These interactions were characterized mainly by displacement of a foraging egret or egrets by a heron. Several foraging related behaviors include hopping, described as a short jump and flight resulting in a simultaneous landing and strike at potential prey. Wing flicking is described as a quick opening flex of a single wing or both wings in an attempt to startle prey into motion and make it visible to the foraging heron (Meyerriecks 1960a:89). 


\section{RESULTS}

\section{ANALYSIS OF HABITATS}

The percent time of observed behaviors for each habitat for 1986 and 1987 indicate general trends within and between habitats (Figures 2 and 3). The Salicornia flats and islands habitats are similar: the highest percent time of observed behaviors is the hunched stand and wait. These habitats are markedly different in the percent time in both the upright stand and wait behavior and the other behavior category. The Salicornia flats has higher time observed in the other behaviors while the islands habitat has a higher time observed in the upright stand and wait. Unlike the Salicornia flats and islands habitats, the inland shallows, main channel and Mud Flat habitats have low times in the hunched stand behavior. Similarly these three habitats have high times utilizing the upright stand and wait behavior. Also, these habitats have higher times in the crouched stand and wait and walk slowly crouched behaviors. 
Figure 2 Percent Time of Observed Behaviors

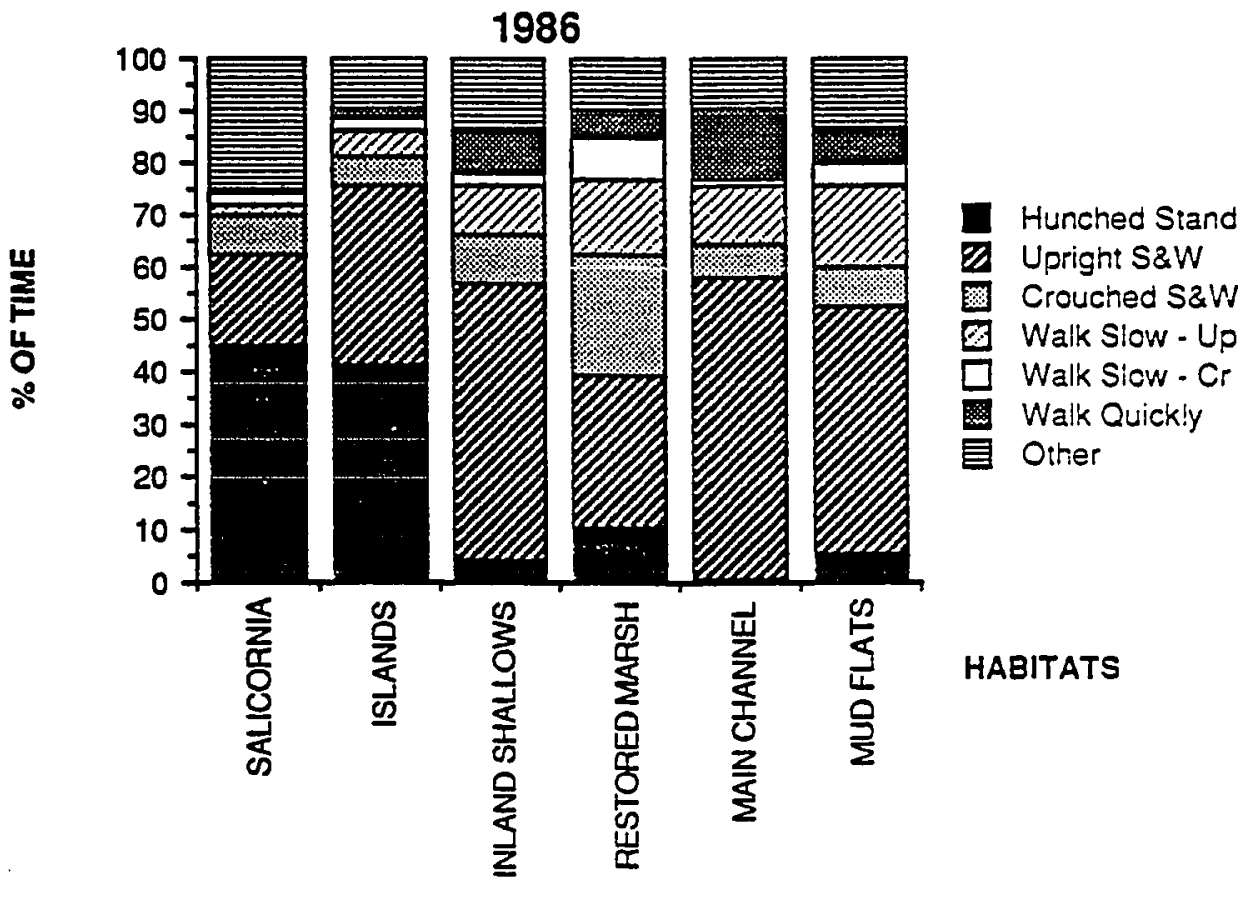


Figure 3 Percent Time of Observed Behaviors

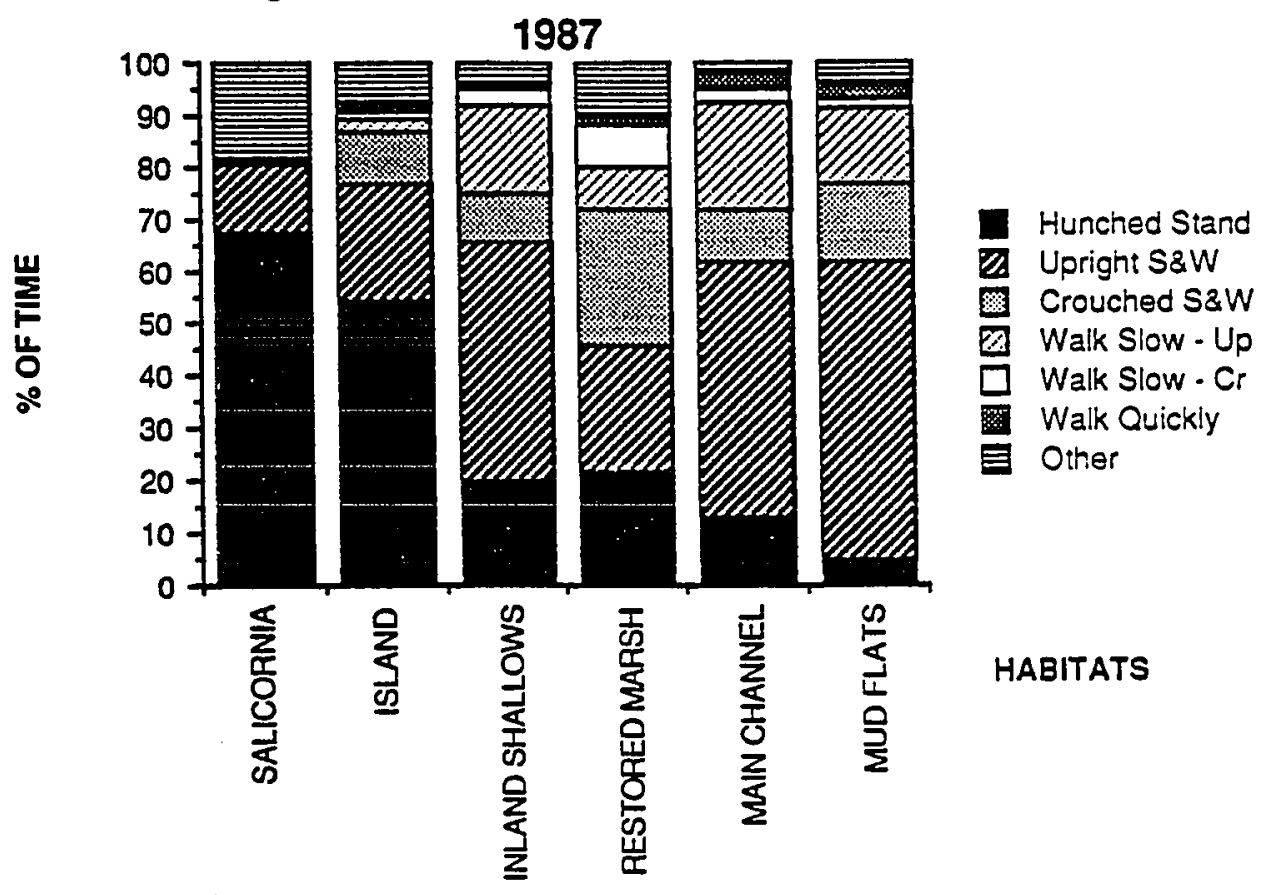


The most noticeably different habitat, as far as percent time of observed behaviors, is the restored marsh. The restored marsh has a high percent time in both upright stand and wait and crouched stand and wait. Also, this habitat has the highest percent time in the walk slowly crouched behavior of any habitat. Combined data for both 1986 and 1987 were used in Anova testing to reveal significant patterns between habitats and behaviors. Four habitats -- the Salicornia flats, the islands, the restored marsh, and mud flats -- had distinct behavioral patterns within each habitat (Figure 4.). These patterns within also reveal different behavioral patterns between habitats. In general the inland shallows and main channel closely parallel the behavioral patterns of the mud flats habitat.

Behavioral patterns exist between habitats. Four behaviors -- hunched stand, upright stand and wait, crouched -- stand and wait, and walk slowly crouched reveal these differences between habitats (Figure 5). The walk quickly behavior did not have any significant patterns between habitats. The behavior "other" showed a significant difference in time observed in the Salicornia 
flats. All other habitats, except the islands habitat, were significantly lower in observed time of the "other" behavior.

Significant differences $(P<.05)$ in foraging success and prey size exist between habitats for both 1986 and 1987 (Tables 1 - 2). 
Behaviors

\section{Hunched Sland Upright Stand/Wait Crouched Stand/Wait Walk Slowly Upright Walk Slowly Crouched Walk Quickly Other}

Hunched Stand
Upright Stand/Wait
Crouched Stand/Wait
Walk Slowly Upright
Walk Slowly Crouched
Walk Quickly
Other

Hunched Stand Upright Stand/Wait Crouched Stand/Wait Walk Slowly Upright Walk Slowly Crouched Walk Quickly Other

Hunched Stand Upright Stand/Wait Crouched Sland/Wait Walk Stowly Upright Walk Slowly Crouched Walk Quickly Other
Habitats

Salicornia Flats

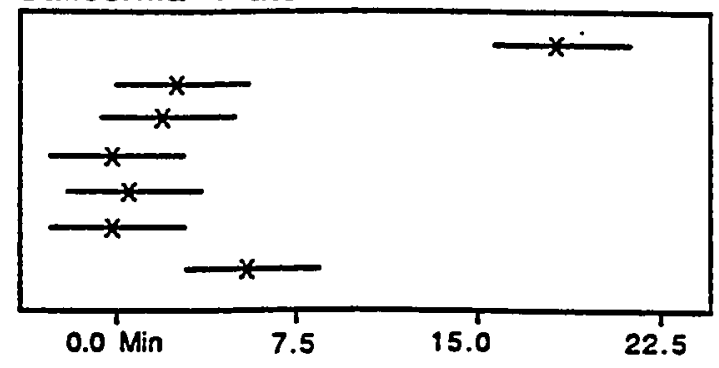

Islands

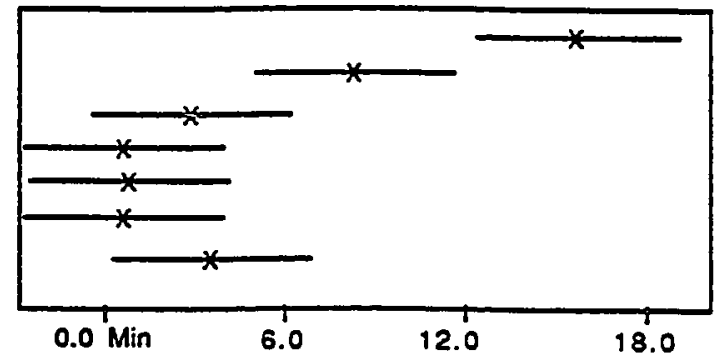

Restored Marsh

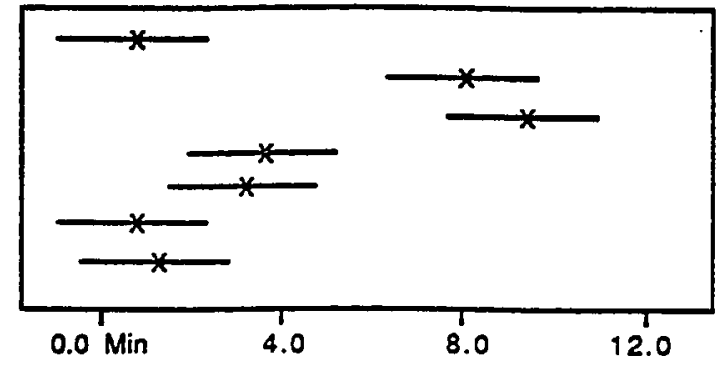

Mud Flats

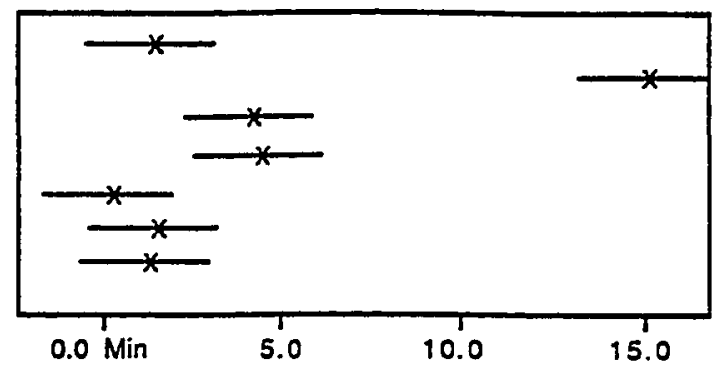

Figure 4. Comparisons of Observed Behaviors Within Each Habitat ( $P<.05$ Based on pooled standard deviations). 
Habitats

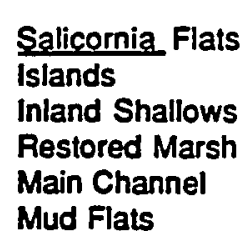

Salicornia Flats Islands

Inland Shallows Restored Marsh Main Channel Mud Flats

\section{Salicomia Flats Islands Inland Shallows Restored Marsh Main Channel Mud Flats}

\section{Behaviors}

Hunched Stand

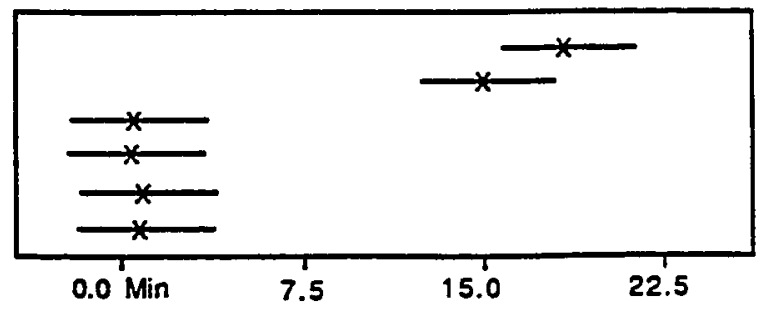

Upright Stand and Wait

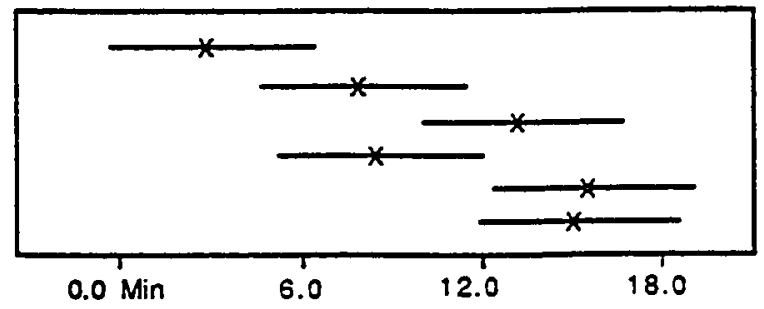

Crouched Stand and Wait

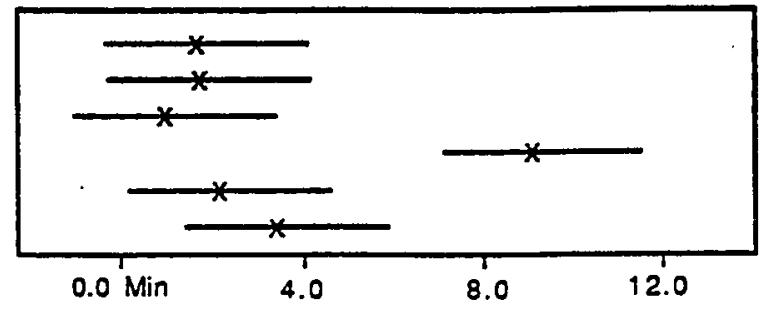

Walk Slowly Crouched

Salicornia Flats Islands Inland Shallows Restored Marsh Main Channel Mud Flats

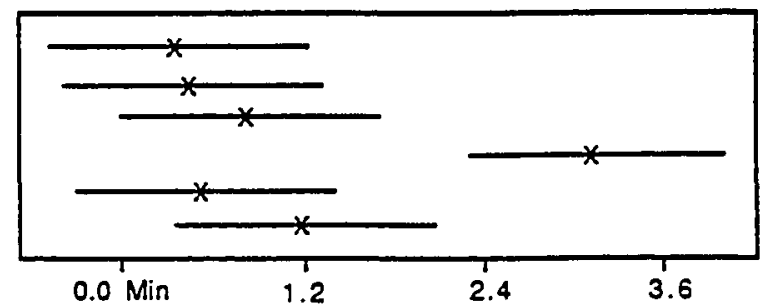

Figure 5. Comparisons of Observed Behaviors Between Habitats ( $P<.05$ Based on pooled standard deviations). 


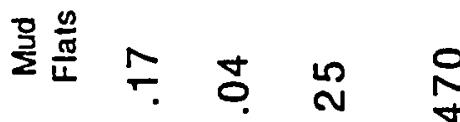

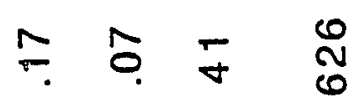

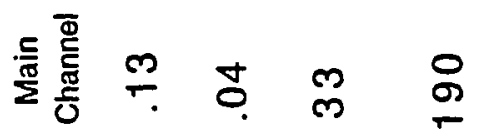

$=0 \quad n \quad n$

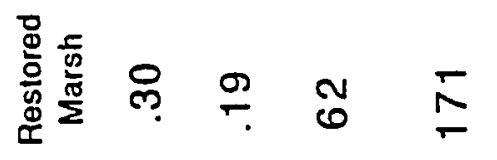

g.

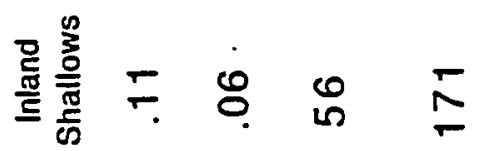

$\because \underset{0}{N} \stackrel{0}{0}$

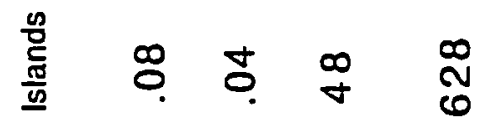

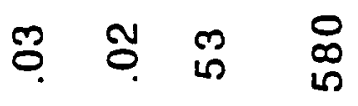

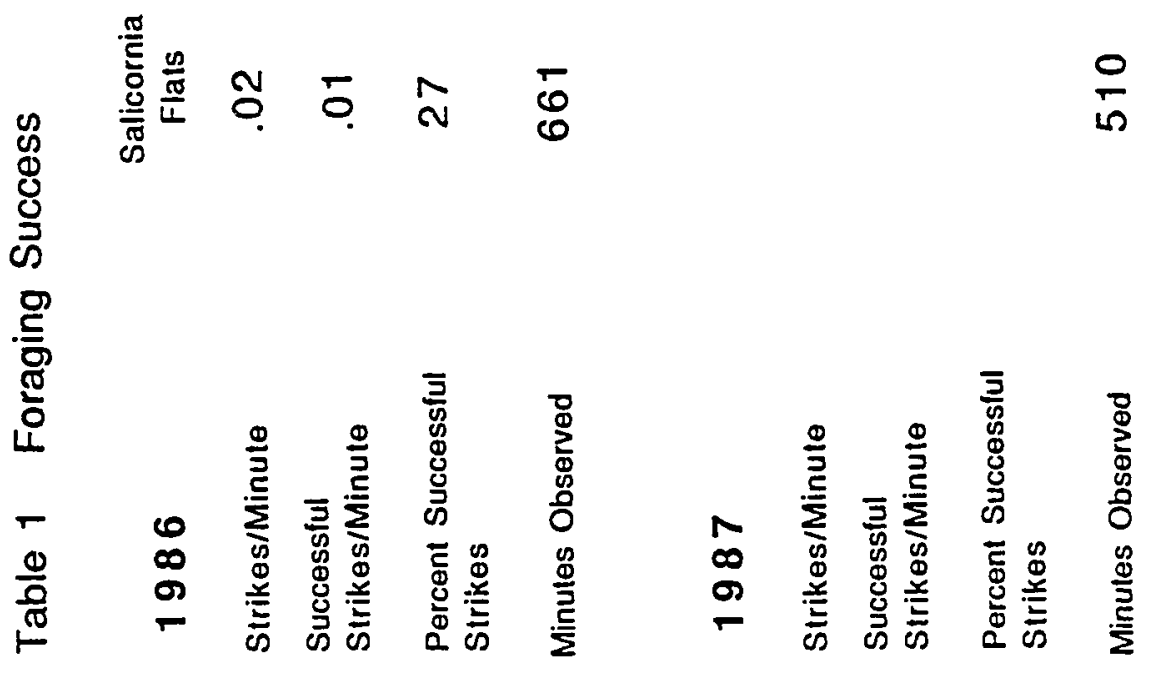




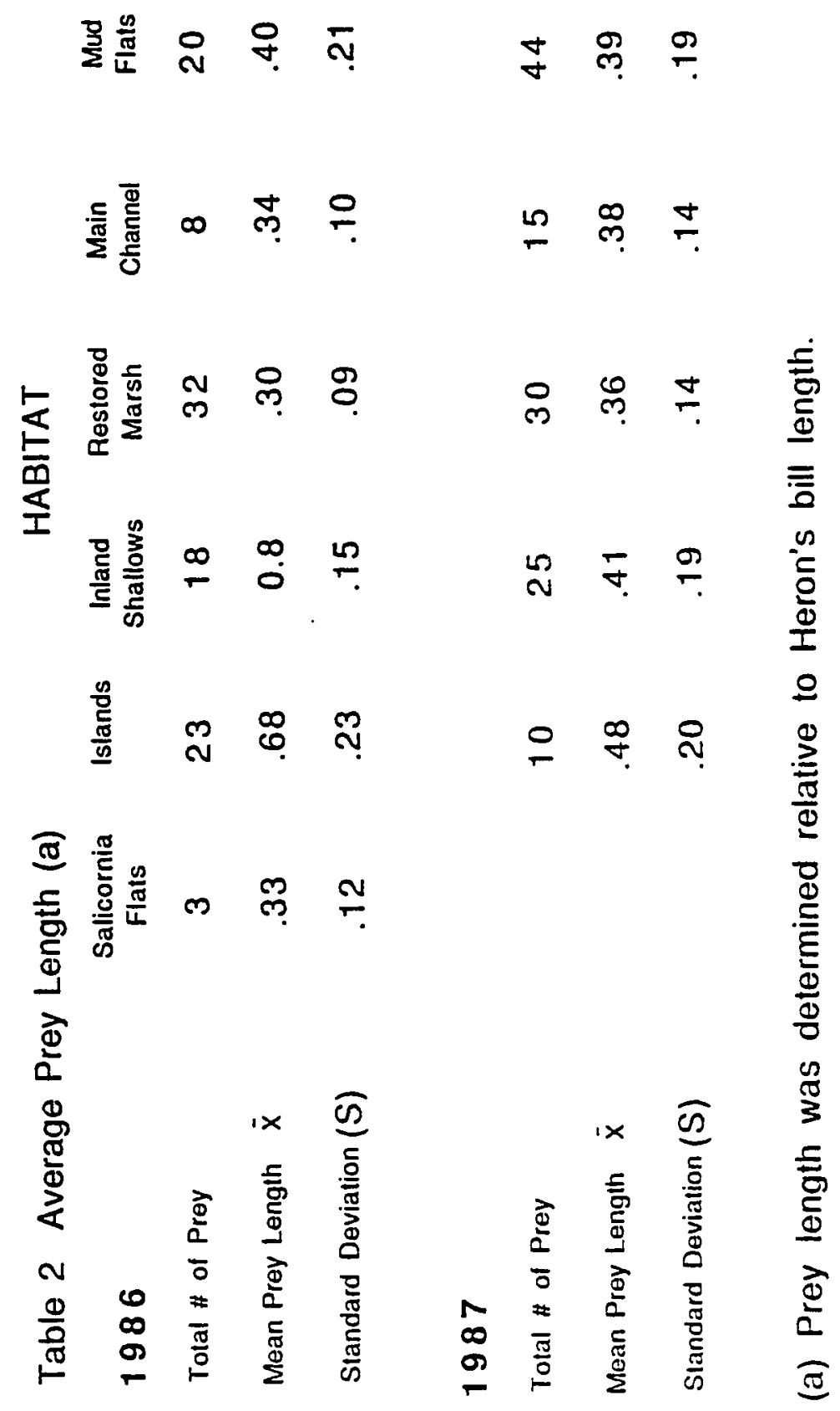


Total strikes per minute of observation in each habitat during 1986 were significantly different. The Salicornia flats habitat had the lowest strikes per minute value of any habitat. The islands habitat had a greater strikes per minute value than the Salicornia flats, yet both were lower than those of all other habitats. The restored marsh habitat had the highest strikes per minute of any habitat. The main channel habitat and mud flats had significantly lower strikes per minute than the restored marsh, yet both had greater values than the remaining häbitats.

The successful strikes per minute in two habitats were different from the other habitats. The Salicornia flats had the lowest successful strikes per minute; the restored marsh had the highest successful strikes per minute. The percentage successful strikes values also indicate a significant difference between habitats. The inland shore, island levee and restored marsh habitats, although not significantly different between themselves, were significantly greater in percent successful strikes than the Salicornia flats, main channel and mud flats habitats.

Prey size for 1986 was significantly different between the 
habitats. The isiands and inland shallows habitats had greater mean prey size compared to the remaining habitats. The inland shallows had the highest mean prey size and was significantly greater than the islands habitat (Table 2).

Significant differences $(P<.05)$ of total strikes per minute exist between several of habitats during 1987. The major differences occur between the mud flats with the greatest strikes per minute and the Salicornia flats with the lowest strikes per minute. The mud flats are significantly greater than all habitats except for the inland shallows habitat. However, the inland shallows habitat is not significantly different from the islands, restored marsh and main channel habitats. The Salicornia flats, as in the 1986 data, are markedly lower in strikes per minute than all other habitats in 1987.

Successful strikes per minute were different between several of the habitats. The main channel had greater successful strikes per minute than all other habitats while the Salicornia flats had the lowest value. The remaining habitats have similar values. The percent successful strikes for 1987 are the same as 1986 . The 
inland shallows, islands and restored marsh have significantly greater values than the remaining habitats. Prey size for 1987 unlike 1986 showed no significant differences between habitats. 


\section{EFFECTS OF WEATHER ON FORAGING}

Foraging success was not significantly affected by wind (Table 3). Total strikes were no more frequent when winds were calm than when winds were high (Table $3 ; \mathrm{t}=1.65, \mathrm{t}=.385, \mathrm{P}<$ .05). Prey size was not significantly affected by wind during 1986 (Table $4 ; \mathrm{Z}=.538, \mathrm{P}<.05$ ), but during 1987 , was significantly affected by wind $(Z=2.30, P<.05)$. Larger prey was more frequently caught during calm winds in 1987.

Foraging success was significantly affected by cloud cover (Table 5). Total strikes were more frequent on clear days $(t=$ $6.82, \mathrm{t}=4.77, \mathrm{P}<.001)$. Successful strikes were also more frequent during clear days $(\mathrm{t}=5.34, \mathrm{t}=4.03, \mathrm{P}<.001)$. Prey size was not significantly affected by cloud cover in either year (Table 6). 
Table 3 Effects of wind on foraging success

\section{6}

Strikes/Minute

Successful

Strikes/Minute

Percent Successful

Strikes

Minutes Observed
Calm Windy

$.09 \quad .11$

$.04 \quad .05$

$43 \quad 43$

$1680 \quad 780$

\section{7}

Strikes/Minute

$.08 \quad .08$

Successful

Strikes/Minute

$.04 \quad .03$

Percent Successful

Strikes

$48 \quad 35$

Minutes Observed

$1710 \quad 1170$


Table 4 Effects of wind on relative prey size(a)

1986

$$
\text { Calm Windy }
$$

Total \# of prey $\quad 58 \quad 27$

Mean prey length $\quad .40 \quad .46$

Standard deviation $\quad .38 \quad .22$

\section{7}

Total \# of prey $\quad 74 \quad 46$

Mean prey length $\quad .42 \quad .35$

Standard deviation $\quad .18 \quad .15$

(a) Prey length was determined relative to heron's bill length. 
Table 5 The effects of cloud cover on foraging success

Calm Windy

1986

$\begin{array}{lcc}\text { Strikes/Minute } & .14 & .05 \\ \begin{array}{l}\text { Successful } \\ \text { Strikes/Minute }\end{array} & .06 & .02 \\ \begin{array}{l}\text { Percent Successful } \\ \text { Strikes }\end{array} & 43 & 33 \\ \text { Minutes Observed } & 990 & 1110\end{array}$

1987

Strikes/Minute

$.10 \quad .05$

Successful

Strikes/Minute

$.05 \quad .02$

Percent Successful

Strikes

$45 \quad 35$

Minutes Observed

$1560 \quad 1170$

(a) Cloud cover was determined by percentage of cloud cover over visable sky, Clear $\leq 25 \%$, Cloudy $\geq 50 \%$. 
Table 6 Effects of cloud cover on relative prey size

\begin{tabular}{|c|c|c|}
\hline & \multicolumn{2}{|c|}{1986} \\
\hline & Clear & Cloudy \\
\hline Total \# of prey & 66 & 15 \\
\hline Mean prey size & $\bar{x} \quad .47166$ & .566 \\
\hline Standard Deviation & (S) .25600 & .24445 \\
\hline
\end{tabular}

\section{7}

Total \# of prey $\quad 86 \quad 35$

$\begin{array}{llll}\text { Mean prey size } & \bar{x} & .40116 & .36714\end{array}$

Standard Deviation (S) $.17429 \quad .18412$ 


\section{EFFECTS OF TIDE ON FORAGING}

Overall foraging success was not significantly affected by tidal height. Although total strikes were significantly more frequent during low tide than high tide only during 1986 (Table $7 \mathrm{t}=8.12, \mathrm{P}<.001$ ). Neither successful strikes nor prey size were significantly affected by tide during 1986 and 1987 (Table 8). 
Table 7 The effects of tidal height on foraging success

\section{6}

Strikes/Minute

Successful

Strikes/Minute

Percent Successful

Strikes

Minutes Observed

\section{7}

$\begin{array}{lcc}\text { Strikes/Minute } & .10 & .09 \\ \begin{array}{l}\text { Successful } \\ \text { Strikes/Minute }\end{array} & .04 & .04 \\ \begin{array}{l}\text { Percent Successful } \\ \text { Strikes }\end{array} & 43 & 43 \\ \text { Minutes Observed } & 1548 & 844\end{array}$


Table 8 Effect of tidal height on relative prey size

\section{6}

$\begin{array}{lcc} & \text { Low } & \text { High } \\ \text { Total \# of prey } & 50 & 11 \\ \text { Mean prey size } \quad \bar{x} & .44 & .34 \\ \text { Standard Deviation (S) } & .258 & .220\end{array}$

\section{7}

$\begin{array}{lccc}\text { Total \# of prey } & 79 & 13 \\ \text { Mean prey size } \bar{x} & .39 & .43 \\ \text { Standard Deviation (S) } & .180 & .167\end{array}$




\section{DISCUSSION}

The complexity of the estuarine habitats of Elkhorn Slough provides the foraging herons with a variety of choices. As expected, the herons temporal and spatial use patterns are highly variable (Richner 1986). The main patterns drawn from the results reveal major differences between two of the six habitats. The Salicornia flats and the islands habitat both are used primarily for non foraging activities. Of the remaining four habitats all are primary foraging habitats. One of these, the restored marsh, herons utilize with the greatest range of behaviors.

The foraging success also varies from habitat to habitat. The foraging success supports and reflects the behavioral patterns of each habitat. The non foraging habitats have low values while the remaining foraging habitats have higher success rates. The foraging success of these primary foraging habitats vary and reflect the nature of the habitat as well as the 
availability of prey, and prey type. The prey size of each habitat does not reflect the behavioral patterns of the habitats nor does it necessarily reflect the foraging success of each habitat.

The weather patterns and tidal actions of the slough are variable yet had little influence upon foraging behavior or success. Winds presumably reduce the visibility of fish beneath a rippled surface (Bovino and Burtt 1979), yet foraging success was not reduced during 1986 and 1987 . The effects of clear skies opposed to overcast skies on foraging success are contrary to expected and those observed by (Bovino and Burtt 1979). Foraging success was greater during clear skies. Tides influence all slough habitats to some extent and in turn influence the foraging behaviors of herons. Yet foraging success was not noticeably affected by tidal height.

The Salicornia flats is not a primary foraging habitat, yet is important for loafing behavior and social interactions. The dominant behavior is the hunched stand which is closely associated with loafing. Much of a loafing heron's time on the Salicornia flats is spent preening. Social behavior occurred in the 
form of displacement flights by one heron directed at another. Since this habitat is not a foraging area, these social interactions are only indirectly associated with territoriality at foraging habitats as described by Cook (1978) and Richner (1986). These aggressive acts occur at foraging habitats and suggest that some territoriality is present. One social interaction, the wing out behavior, was only observed in the Salicornia flats. This behavior is a direct confrontation between two herons within close proximity. This behavior frequently resulted in one bird moving away in an alert upright walk, or flying a short distance before assuming an alert upright posture. This social interaction may determine a social hierarchy among loafing herons that influences territories and dominance in foraging habitats.

An important function of the Salicornia flats may provide a staging area for early courtship and nesting. The large social gatherings of up to 12 individuals in early February of both 1986 and 1987 may have been important in restoring the nesting colony in the slough. These gatherings may provide the herons with a gauge of nesting readiness. These groups may help recruit 
other herons to the area and into the breeding population. It has been shown by Hafner ( ? ), Krebs (1974) and Kushlan (1977) indicate that live decoys as well as model herons attract free flying herons. In this context, the Salicornia flats, although not a primary foraging habitat, is likely important to the stability and growth of the heron population in Elkhorn Slough.

Within the islands habitat the hunched stand behavior was the most frequently observed, followed by the upright stand and wait behavior. Like the Salicornia flats, the islands habitat is not a primary foraging area. Unlike the Salicornia flats the island habitat is used as a secondary foraging area. The upright stand and wait occurred in or at water's edge along with the crouched stand and wait. These long term motionless behaviors would facilitate foraging of mobile prey. Active foraging behaviors would only serve to startle mobile prey beyond the striking range of a heron. Standing and waiting for mobile prey to move within a strike zone is the most efficient means of foraging in the islands habitat. Actual foraging time within this habitat was low, indicated by few strikes per minute, yet the herons were 
successful when foraging.

Herons use the variety of conditions provided by the islands habitat for loafing and foraging. The exposed islands provide a refuge for resting herons while the channels between islands provide a continuous foraging habitat, determined by the ebb and flow of tide and prey. A heron must invest a great deal of time waiting for mobile prey to move within the habitat. This would encourage herons to maintain a small territory while discouraging other herons from displacing the residing heron since little is gained in the short term. This may explain the low interactions between herons in the islands habitat reflected in the low time spent in other behaviors.

The inland shallows is the least utilized habitat. This is a result of the difficulties encountered by a foraging heron. Although the habitat is influenced by tide, a low tide does not create a more suitable foraging habitat. The shallow sloped banks and relatively deep water make foraging on either schooling or sedentary prey difficult. Herons utilized the stand and wait behavior the most, either on the mud banks or in water normally 
less than half a meter in depth. This behavior, as in all habitats, is a primary foraging strategy for locating moving prey. When used from shore a heron can search for moving prey in shallow water. The difficulty for the heron occurs when a prey item is identified outside the heron's immediate strike range. The walk upright is the most frequently observed active foraging behavior in the inland shallows. Yet active pursuit on shore or upon entering the water encourages escape of sedentary prey to deeper water inaccessible to the heron. The depth and turbidity of the open water in the inland shallows makes foraging on bottom dwelling sedentary prey difficult. The upright walk in open water does not provide a foraging heron with the ability to capture fleeing prey as in the shallow water habitats. This is unlike the foraging conditions in the mud flats where the upright walk is used to pursue fish in confined shallow pools. Standing and waiting in the open water of the inland shallows provides the opportunity to forage on mobile prey. This is similar to the foraging behavior in the islands habitat where herons are also foraging for mobile prey in deep water. Motionless foraging allows a heron to strike at 
prey within the immediate area. This is a benefit and is reflected in the high successful strikes per minute and high percentage of successful strikes. The low strikes per minute in the inland reflects the investment of time required to forage on unpredictable mobile prey. The inland shallows is not the most productive foraging as indicated by low overall foraging success and relatively low usage by herons.

The restored marsh is an important foraging habitat for the herons of Elkhorn Slough. The restored marsh provides a rich foraging habitat as revealed by the highest strikes per minute and highest successful strikes per minute of any habitat. This foraging success suggests that the herons are effectively utilizing this habitat to meet the demands of nesting.

The foraging methods used by herons in the restored marsh are markedly different than in other habitats. The upright stand and wait is the most often observed behavior, as in the other foraging habitats, yet it is often replaced by the crouched stand and wait behavior in the restored marsh habitat. The increase in the crouched stand and wait is related to this unique habitat. 
Unlike the other foraging habitats, the restored marsh has submerged vegetation, namely Salicornia, that provides ample cover for fish. Along with an increase in the crouched stand and wait there is an increase in the walk slowly crouched behavior. These crouched behaviors would allow herons to seek out prey in the submerged vegetation and strike quickly at prey as it escapes into cover. The crouched behaviors allow rapid strikes since little time is lost crouching down from an upright stance into the striking stance. The total strikes per minute indicate high foraging activity while the high rate of successful strikes per minute reveal the advantages of foraging in the crouched position in this habitat. The observed walk slowly upright behavior often followed periods of active foraging and seems primarily used in locating new undisturbed patches of prey.

The time spent in the "other" behavior category indicates that interactions between foraging herons in the restored marsh did occur. Although the habitat is large and seemingly can support a number of herons, intraspecific competition limits the number of herons that can successfully forage. Of the observed 
interactions, most involved direct encounters and aerial chases. The relative stability of this habitat and its foraging advantages encourage herons to defend a foraging area. The duration a heron maintains a foraging area is determined by the amount of habitat switching that occurs. Although the foraging success is high in the restored marsh, the relative prey size was the smallest of any habitat; thus it may be most efficient to switch and forage in other habitats during advantageous tides or seasonal changes in prey populations. Richner (1986) found that herons switching between two different foraging habitats achieved a significantly higher food intake than birds that used only one habitat.

The restored marsh habitat is the most unique foraging habitat. Although the shallow channels and standing water would support similar prey as the mud flats the foraging strategies is markedly different. The lack of open waters may restrict large fish from utilizing this habitat. This is reflected in the small prey size captured by the herons.

The mud flats and main channel are utilized in similar ways by foraging herons. At first glance these two habitats appear 
nothing alike: the main channel with water flowing from bank to bank, the mudflats with a large expanse of shallow standing water. The link between these two habitats is the effect of tide that alters and provides similar foraging habitats for herons. The main channel is an ideal habitat for schooling prey, yet the herons are forced by the tide to forage along the steep mud banks, shallow shoals and small channels suited for sedentary prey. The mud flats are inaccessible at high tides, yet provide shallow pools, channels and flats during low tide. The habitat is ideal for sedentary prey and like the main channel has a long renewal time, restricting herons to forage only during falling and low tides. The mud flats habitat is continually flooded and drained by the tides. This changing habitat is dominated by Goby species and Sculpin species. Therefore, herons utilize this shallow water habitat to forage on burrowing and sedentary prey.

While the herons' foraging behaviors differ between subhabitats many of the similarities of the sub habitats can be explained by different prey compositions throughout the slough habitat. Fish composition varies between the main slough and 
tidal creeks, as well as intertidal areas that are occasionally completely drained (Barry 1983). Therefore, it is likely that both behavior specialties displayed by foraging herons and type of habitat lead to differences in prey taken (Willard 1977). The islands, and inland shallows habitats are similar habitats for prey species. Both have deep water channels and are connected distantly to the main channel. These habitats seem more suitable for schooling prey, such as Topsmelt Atherinops affinis, Northern Anchovy Engraulis mordax and Pacific Herring Clupea pallasii.

The main channel, although similar to the deep water inland habitats, has greater prey diversity due to its larger expanse, and thus greater spatial heterogeneity. These factors, coupled with the stable ocean characteristics, host a less restricted fish fauna than inland channels (Barry 1983). These three habitats may support similar prey species which is reflected in the similar foraging behavior and success of herons. Unlike the islands and inland shallows, the main channel is also similar to the mud flats as falling tides expose mud shoals. Therefore, foraging strategies similar to the mud flats are also present. 
Winds presumably reduce the visibility of fish beneath a rippled surface (Bovino and Burtt 1979), yet foraging success was not reduced during 1986 and 1987. Presumably, visibility of prey when wind rippled water surfaces and water turbidity exist would greatly reduce the foraging success of herons in certain habitats. These results are contrary to the Bovino and Burtt (1979) study in which foraging success was markedly affected by wind. Why? Are fish more active near the surface on windy days, allowing herons to capture prey near the surface rather than below the surface? On windless days fish may be less active. If so, this may partially explain why larger fish were caught on windless days during 1987. Larger fish would be more likely seen under the surface, compared to smaller fish. An observed behavior that directly reduces the effects of wind was the use of natural wind breaks by foraging herons. By foraging on the lee side of levees and islands, herons were able to forage in relatively calm water, thus increasing their chance of visually locating prey beneath the surface. Perhaps the most likely reason wind did not have an effect on foraging success is the inability to isolate and 
observe a single element from the ever changing habitat of a foraging heron.

The effects of clear skies opposed to overcast skies on foraging success are contrary to expected and those observed by (Bovino and Burtt 1979). Sunny days can reduce the herons' ability to see prey below on near the water surface. Occasionally herons attempt to reduce glare off the water by tilting their head and neck to varying angles (Krebs and Patridge 1973). This behavior was noticed most frequently when herons were in the crouched stand and wait, and walk slowly crouched behaviors. Furthermore, the dark coloring of a Great Blue Heron is more conspicuous against a clear sky than that of a light colored bird. Yet, the observed herons had a greater foraging success during clear skies. Possibilities of heightened fish activity or attractiveness towards shadows by fish as described by Meyerriecks (1962) may explain the foraging success of the herons on clear days. The adaptive nature, varied habitats, and physical factors affecting heron foraging make it difficult to isolate a single element to determine its effect on foraging. 
On rainy days foraging was rarely observed in any habitats. Herons were observed loafing in the Salicornia flats or in the hunched stance in the other habitats. Rain directly affects herons' ability to forage in the disturbed water surface. On four different occasions, herons were observed stalking on the grassy fields during rain showers. Several of these herons were observed pursuing vocalizing frogs. Although successful strikes were not observed, this foraging behavior is an example of the adaptability of herons to maximize their foraging in adverse conditions.

Tides influence all slough habitats to some extent and in turn influence the foraging behavior of herons. The tidal influences were documented during 1986 in which total strikes were more frequent during low tide. Tidal heights are not consistent throughout the slough; lag times between the main channel, and the mud flats and inland shallows are variable in time and duration. Thus, herons move out of habitats inundated by incoming tides to habitats not yet affected by the changing tide. Herons also utilized the restored marsh habitat that is not greatly affected by tides. 


\section{SUMMARY}

The herons of Elkhorn Slough are utilizing different foraging strategies within the sub-habitats to maximize foraging success. Therefore, the choice to forage in a particular habitat in this complex system affects both foraging success and size of prey captured. Weather played a small role in affecting foraging strategy and success. Tidal influences affect foraging directly by altering several sub-habitats to the point of being inaccessible at high tide. Herons are well adapted to make decisions about a variety of habitats, physical factors and appropriate behaviors to successfully utilize the available prey. 


\section{LIFE HISTORY}

\section{INTRODUCTION}

I examined the renewed nesting of Great Blue Herons within the Elkhorn Slough National Estuarine Sanctuary (ESNES) to determine the success of nesting and possible factors contributing to recurrence of nesting. Nesting has occurred sporadically in several areas within the slough in recent times; it has been roughly 30 years since the currents site was an active rookery.

\section{METHODS}

Regular counts were made of Great Blue Herons on the newly established colony before and during the breeding season which occurs from mid February to July. The proportions of adult to second year birds at the colony were observed during the breeding season to determine the number of breeding individuals. The height and inaccessibility of nesting trees made nest counts 
from the ground difficult and breeding states hard to determine. Although all the active nests were not visible, observation of nesting herons did provide information about nest building, incubation and first hatching, estimates of chick age, clutch size and approximate numbers of fledglings.

\section{RESULTS}

Pre-breeding Behavior

Relatively few Great Blue Herons occupied the sanctuary through the winter. Foraging occurred over the entire Elkhorn Slough habitat during this season. During January of 1986 and 1987 the numbers of birds remained low and no intraspecific behavior was observed. On February 2, 1986 and February 2, 1987, groups of herons were first observed loafing and interacting in the Southern Salicornia flats. Numbers of herons increased during February and as many as 12 individuals were observed loafing in loose groups. Along with the increasing number of herons, an increase of threat displays and inflight chases occurred. These aggressive behaviors were most frequently observed 
among the groups of herons loafing in the Salicornia flats.

Aggressive behavior also occurred in other habitats among individuals.

Nesting Behavior

Prior to 1986 , only one pair of herons were reported nesting in Elkhorn Slough in 1985. As this study began there was no evidence to indicate nesting would occur in 1986. Likely nesting sites were frequently observed in the beginning of this study. A small grove of Monterey Pines (Pinus radiata) toward the North end of the sanctuary received attention since it was the location of the 1985 sighting. Also, this location was discovered to have been the site of a previous nesting colony of herons in the 1950's.

On February 27, 1986 and February 9, 1987 a group of herons were first observed roosting in the Monterey Pine grove. During the rest of February and early March, courtship behavior was observed. Pair formation and associated behaviors and vocalizations, as described by Cottrille and Cottrille (1958) occurred. Sudden flights, described by Cottrille and Cottrille 
(1958) and Pratt (1970), by as many as 27 individuals occurred several times during the early stages of pair formation courtship.

Stick carrying is a behavior associated with pair bonding, copulation and nest construction (Ives 1972). Herons carried sticks from the canopy of an adjacent Eucalyptus grove to the nest sites through late February and March. Short circle flights associated with establishing nest territory and pre-copulatory behavior (Mock 1976) occurred during March of 1986 and 1987. On March 11, 1986, the first nests were located within the canopy of the pines. A total of 10 nests were counted on July 13, 1986. The following year on March 16 a total of 12 nests were counted. The nests were $30-40$ meters above the ground and roughly a half meter in diameter of loosely stacked branches. During the early stages of pair formation and nest construction activity increased at the rookery, and among the groups of herons on the Salicornia flats.

Incubation and Brooding of Young The first indication of incubation during 1986 was on March 
13. Incubation duties are performed by both sexes for 28 days. Further indications of incubating herons occurred on March 18 as 8 birds were startled from nest sites at the sound of a gun shot. These birds circled the nest sites and quickly returned. Egg laying and incubation took place from late March through the middle of April. Few short circling flights and little stick carrying behavior occurred in early April.

On April 16 fragments from four recently hatched eggs were found below the nest sites, and chick vocalizations from two were heard on this day. Also, at least five other herons continued incubating or brooding.

Depending on weather conditions, brooding of hatchlings is nearly continuous until they reach 2 weeks of age. At this age the attending adult was often at nests edge, preening and waiting for its mate to return from foraging. On June 4, one nest contained four 7-8 week olds, a second contained two 4 week olds while a third contained three 4 week old chicks. During this time both adults were frequently away from the nests for extended periods of time. On June 6 , two nestlings perched in branches above a 
nest site while two fledglings loafed in the island levee habitat. From early June through early August fledglings left the nest site to forage in the nearby mud flats and island levee habitats. Begging vocalization was heard at the nest site as late as July 23. During the fledgling period, increased interaction among herons at all habitats occurred. Many of the interactions by adults were aggressive flights and threats directed at the fledged individuals.

The first indication of incubation during 1987 occurred on March 9 when eight herons were observed on nests. On March 15, a total of thirty-two herons roosted in the rookery, again eight herons were seen incubating. The following day 15 herons were roosting in the rookery. On March 19, 12 nests were counted from directly below the rookery. The number of birds at the nesting site remained high through the middle of April. During this time many birds flew in to relieve their mates from incubation duties. Often these exchanges caused a great deal of disturbance of the rookery as mates vocalized and neighboring herons defended their nest site. On April 23, two 2 week old chicks were heard and seen at a nest while seven herons continued to incubate. 
Exchanges of mates at the nest site increased during the end of April. On April 30, chicks were heard vocalizing from several nests. On May 7, three 2-3 week old chicks crouched low in a nest while the attending heron shaded them with extended wings. A single one week old chick vocalized from a nest. Observations of eight nests during May revealed 2-3 chicks of varying ages in six nests. Two nests were occupied by an attending heron. During the end of May the first fledged birds began perching away from the nests, trying their wings. On May 28 three nests contained nine 6-7 week old herons. June through August fledged birds foraged in the mud flats, island levee and inland shores while many returned to the rookery to roost.

\section{DISCUSSION}

The return of a nesting colony in 1986 is partially due to the creation of the restored marsh. Studies on the factors affecting the distribution of heronries (Gibbs 1987, Fasola and Barbieri 1978) and the development or creation of breeding populations (Hafner, Walmsley 1975) conclude: location depends 
on the availability and size of suitable natural wet habitats, while the spacing between heronries is determined by the reduction of intraspecific competition on foraging grounds. Since the closest heronry is along the Watsonville River, there appears to be little competition with the colony at the slough. Therefore, it is likely that the newly developed rookery is due to the increased availability of a good, stable foraging habitat.

The nesting behavior during 1986 and 1987 was consistent with behaviors described by Cotrille and Cotrille (1985), Ives (1972) and others. Of the 10 nests observable in 1986, five nests revealed clutches of varying size. Two nests contained 3 nestlings while the remaining nests had 2 and 4 nestlings each. Obstruction by the tree canopy, concealment by attending adults, and varying states of activity of chicks at the observable nests are the major problems with obtaining accurate counts from the ground. Since all the nests were not observed, only estimates of clutch sizes can be made for the colony. To obtain a rough figure on number of eggs laid and fledgling success data was used from a well studied colony at Audubon Canyon Ranch, Bolinas, California. During a 13 
year study by Pratt and Winkler (1985) the mean clutch size at this northern California colony ranged between 2.72 and 3.35 eggs, with an overall mean of 2.87 . Using these figures, an estimated 30 eggs were laid at the Elkhorn Slough colony during 1986. The overall mean number of fledglings produced at the Bolinas colony was 1.45 , with annual means ranging from .89 to 2.38 fledglings (Pratt and Winkler 1985). Total counts of fledglings range between $6-10$ based on direct observations at the nest sites and at foraging area. Although relatively few fledglings were observed, the numbers of fledglings observed at the Elkhorn Slough Colony fall within the low end of the annual means found at the Bolinas Colony by Pratt and Winkler (1985). Thus, a low fledgling success and the dispersal of young from the nest site to area outside the study area would explain the low fledgling numbers.

During 1987, a total of 12 nests were observed from directly below the nest sites. Eight nests observed from vantage points nearby revealed clutchs of 2 to 3 chicks per nest. Estimates of clutch size from the remaining nests were estimated by 
vocalizations, especially pronounced on the return of adults to the individual nests. Using the Pratt and Winkler (1985) figures of mean clutch size, the estimated number of eggs laid in 1987 was 36. The estimated number of fledglings using the Pratt and Winkler (1985) figures range between 11 and 29. Observations of fledgling numbers at the nest site and foraging ground indicated the number of birds fledged per nest fall near the low end of the range.

There are no clear reasons to explain the low nesting productivity during 1986 and 1987 . There was no evidence of predation at the nest site by either aerial or climbing predators. Crows, a common threat, were not seen at the nesting colony. A nearby pair of nesting Red-tailed Hawks Buteo jamaicensis, were observed harassing herons flying into the colony on several occasions. There was no indication of predation by the hawks on adults or chicks at the colony. Nocturnal predators were present. Both Great Horned Owls, Bubo verginianus, and raccoons Procyon lator, are notorious predators of chicks and eggs, yet no indications of predation were present in the observed nests nor underneath the 
rookery. Although the effects of continued predation can devastate colonies (Pratt 1985, Hjertaas 1982) the effects vary from year to year. Herons are more likely to lose chicks to starvation rather than predation. The only evidence of predation was an adult heron found 500 meters from the nest sites on February 20, 1986 with puncture wounds to the head and bill.

Direct losses to nestling occurred during a wind storm on June 6,1986 where three 4 week old chicks were displaced from their nest. Of these chicks, one survived and was rehabilitated at the Monterey County Society for the Prevention of Cruelty to Animals.

Estimates of nesting mortality are in excess of 40 per cent (Millers 1943). Pratt (1970) found that 4.5 per cent of nestlings known to have hatched died, with most deaths occurring before 4 weeks of age. Competition for food both by foraging herons and by chicks at the nest has the highest impact on mortality. Although competition at foraging sites did occur, displaced birds returned to forage within a short distance and time. Little travel time is required to reach extensive foraging areas from the colony. 
Therefore, nestling mortality occurred due to normal competition among nestlings rather than excessive competition by adults or poor foraging conditions.

The rapid growth of the colony, from a nesting pair in 1985 to 17 active nests in 1987 was unexpected. Similar growth of breeding populations have been found in the Grey Heron populations in Camargue, France. Between 1968 and 1971 a colony grew from 3 breeding pairs to 25 pairs (Walmsley 1975). Although there is additional space available for nesting pairs, as evidence by three unused nests in 1987, further growth of the heronry is limited to expansion to several pine trees adjoining the main rookery.

Aerial photographs of the rookery during May of 1987 reveal 17 active nests and 3 apparently inactive nests (Figures 5 - 6). Of the 17 active nests, 13 were occupied by adult herons. The three inactive nests appear unused, lacking the characteristic white wash of guano unique to the occupied nests. 
These nests are of the previous year or previously abandoned nests from the current nesting year. Ground observations from directly below the colony gave an estimate of 12 nests during 1987 while only 7 nests were clearly observed from ground points around the colony. 


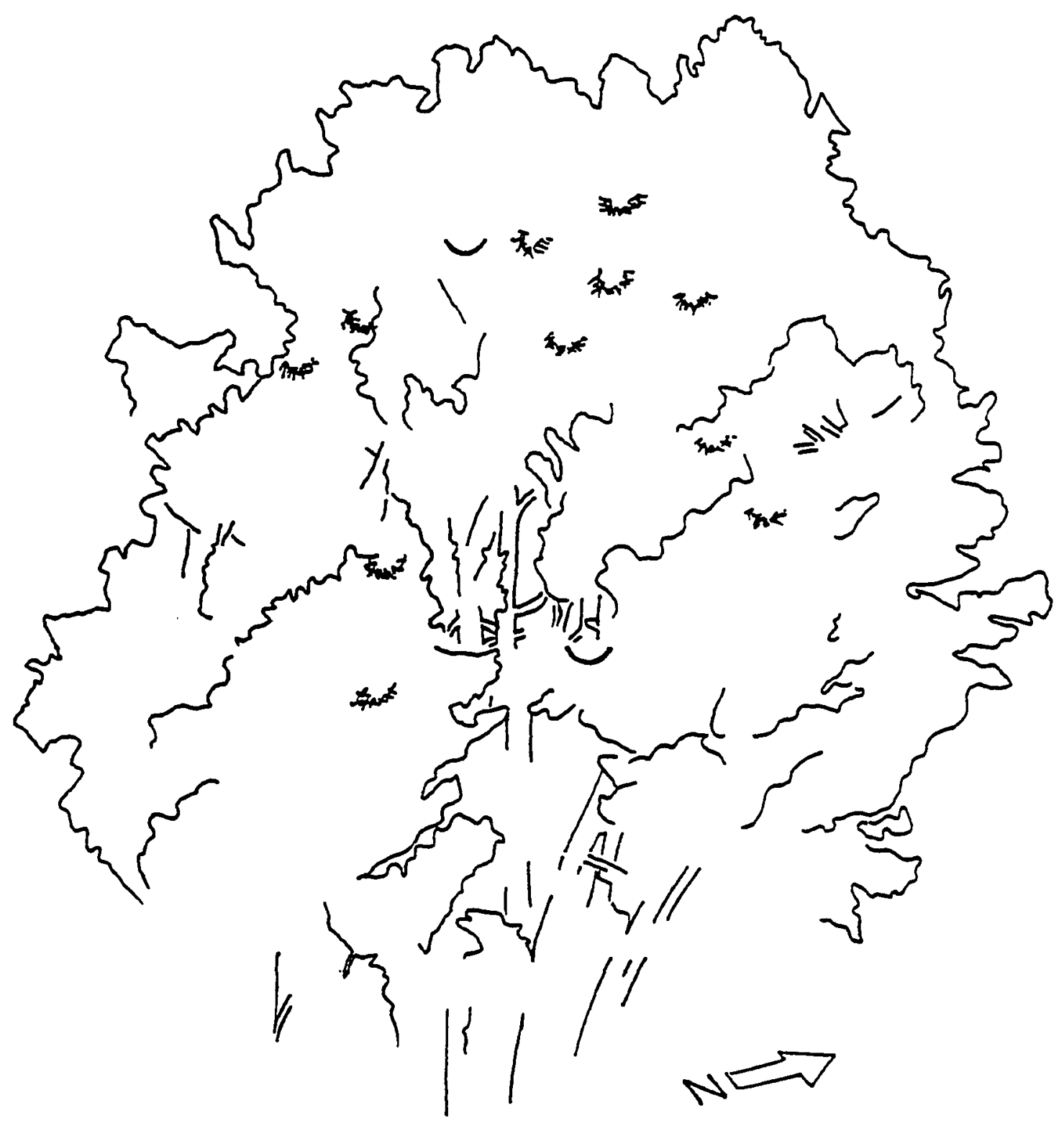

Figure 6. Map of Nesting Colony From Aerial Photograph

Side View 


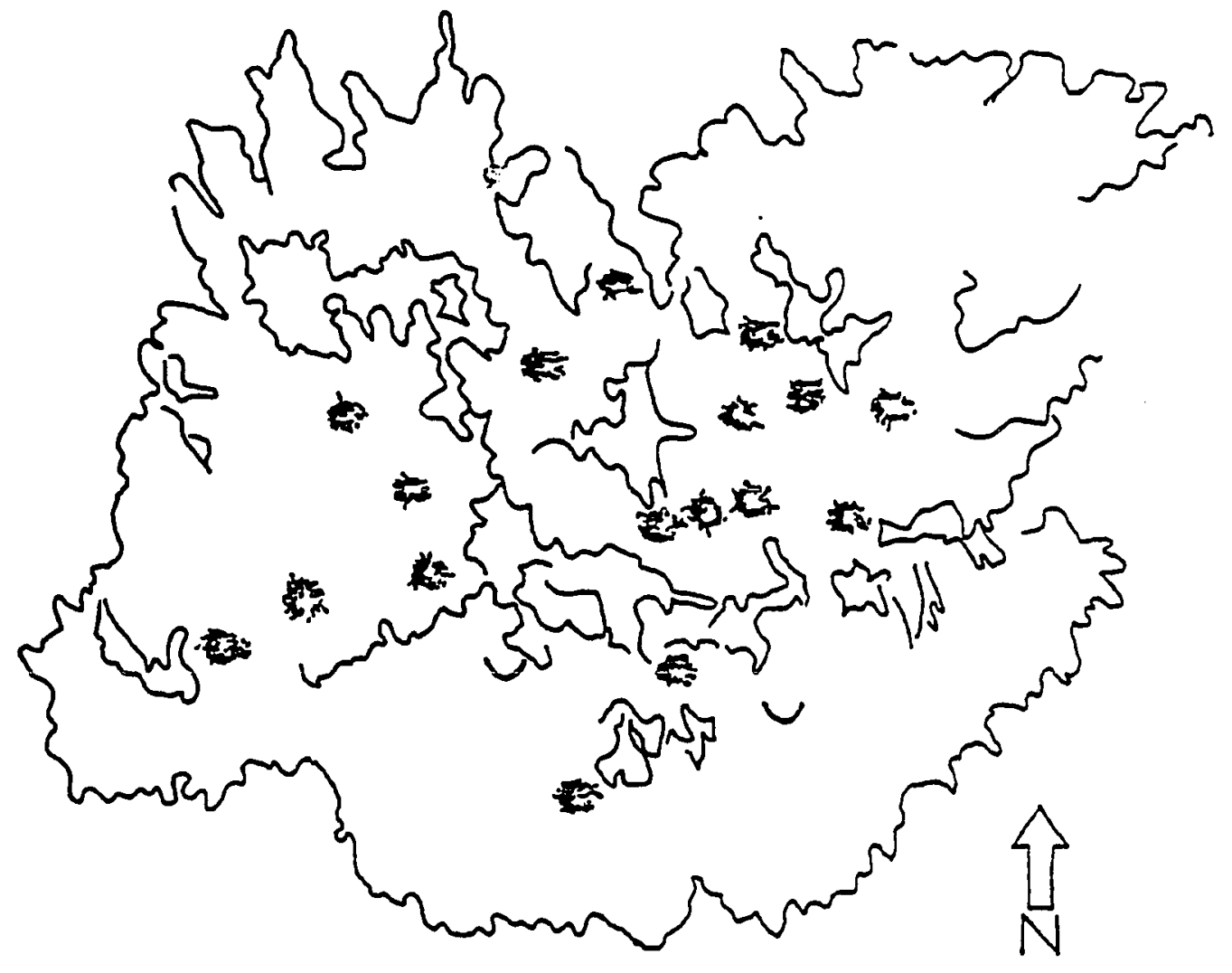

Figure 7. Map of Nesting Colony From Aerial Photograph Top View 
There are discrepancies between what can be observed from ground and what is actually present in a colony nesting in a dense tree canopy. Nests located on the top of the canopy and among heavy branches can easily be concealed from view. Therefore, aerial photographs become an indispensable tool in determining numbers of colonial nesters. Another benefit of aerial photography, as a means of determining nesting numbers, is the relatively low disturbance to the nesting colony. A low flying aircraft alarms nesting herons less than noises originating from ground level (personal observation). Disturbance of a nesting colony must be considered, especially in the early stages of nesting where herons are more apt to abandon nest sites (Henny 1978). Although aerial photography may reveal a great deal about a nesting colony, it may not be feasible and cannot replace careful day to day observations from ground.

\section{SUMMARY}

Foraging decisions become crucial during the nesting season when food is in demand and time limited. The renewed nesting is 
a promising sign that man-made attempts to restore habitats can be successful. The variety of habitats along with newly expanded foraging habitats have played an important role in the re-establishment of the nesting colony. Although ground observations of the colony limit data on nesting success, all indications from the colony are favorable for its future success. 


\section{REFERENCES}

Barry, James P. 1983. Utilization of Shallow Marsh Habitat by Fishes in Elkhorn Slough, California. M.A. Thesis, San Jose State University, 95 p.

Bent, A.C. 1926. Life Histories of North American Marsh Birds. U.S.National Museum Bulletin 135. 392 p.

Boving, R. Russell and Edward H. Burtt. 1979. Weather Dependent Foraging of Great Blue Heron (Ardea herodias). AUK 96:628630.

Browning, B.M. 1972. The Natural Resources of Elkhorn Slough, Their Present and Future Use. Calif. State Dept. of Fish and Game, Coastal Wetland Series \#4, 105 p.

Charnov, Eric L. 1976. Optimal Foraging. The Marginal Value Theorem.Theoretical Population Biology 9:129-136.

Cook, David C. 1978. Grey Herons Ardea Cinerea Holding Feeding Territories on the Ythan Estuary. Bird Study 25:11-16.

cinerea) on the Ythan Estuary. Bird Study 25:17-22.

Cooke, A.S., A.A. Bell and I. Prestt. 2976. Egg Shell Characteristics and Incidence of Shell Breakage for Grey Herons (Aredea cinerea) Exposed to Environmental Pollutants. Environ Pollut. 11:59-84.

Cottrille, W. Powell and Betty Darling Cottrille. 1958. Great Blue Herons Behavior at the Nest. Misc. publ. Museum of Zoology, University of Michigan. No. 102. 
Erwin, Michael R. 1983. Feeding Habitats of Nesting Wading Birds: Spatial Use and Social Influences. The Auk 100:960-970. 1985. Foraging Decisions, Patch Use, and Seasonality in Egrets (Aves: Cicconiiformes). Ecology. 66:835-844.

Fasola, Mauro and Francesco Barbieri. 1978. Factors Affecting the Distribution of Heronries in Northern Italy. Ibis 120:537 -540 .

Fisher, J. 1954. Evolution and Bird Sociality. - In: Huxley, J.S.,A.C. Hardy, E.B. Ford, Eds. Evolution as a Process. London Allen and Unwin.

Gibbs, James P., Susan Woodward, Malcolm L. Hunter, and Alan E. Hutchinson. 1987. Determinants of Great Blue Heron Colony Distribution in Coastal Maine. Auk 104:

Gill, F., and L. Wolf. 1975. Foraging Strategies and Energetics of East African Sunbirds at Mistletoe Flowers. American Naturalist. 109:491-510. ,and 1978. Nonrandom Foraging by Sunbirds in a Patchy Environment. Ecology 58:1284-1296.

Grubb, T.C., Jr. 1976. Adaptiveness of Foraging in the Cattle Egret. Wilson Bull. 88:145-148.

Hafner, H. Managing Wetlands and Their Birds: A manual of active wetland and wild fowl management Ed. D. A. Scott (Chapt. 24).

Hafner, H, Vincent Boy and Gerard Gory. 1982. Feeding methods, flock size and feeding success in the little egret (Egretta garzetta) and the Squacco Heron (Ardecla rallioides) in Camargue, S. France. Adrea 70:45-54. 
Hafner, Heinz and Robert H. Britton. 1983. Changes of foraging sites by nesting little egrets in relation to food supply. Colonial Waterbirds 6:24-30.

Henny, Charles J. and Michael R. Bethers. 1971. Pop. ecology of the Great Blue Herons with special ref.

Henny, Charles J. 1978. Great Blue Herons respond to nesting habitat loss. Wildlife Society Bulletin 6: (1) 35-37.

Howell, D., and D. Hartl. 1980. Optimal Foraging in Glosophagine Bats: When to give up. American Naturalist 115:696-704.

Hom, Calvin W. 1983. Foraging Ecology of Herons in a Southern San Francisco Bay Salt Marsh. Colonial Waterbirds 6:37-44.

Ives, Jonathon H. 1972. Common Egret and Great Blue Heron nest study Indian Island, Homboldt Co. CA 1971-1972. Dept. of Fish and Game. Wildlife Management Branch Admin. Report No. 72-9 (Nov. 1972).

Jenni, D.A. 1969. A study of the ecology of four species of herons during the breeding season at Lake Alice, Alachua County, Florida. Ecol. Monogr. 39:245-270.

Krebs, J.R. and B. Partridge. 1973. Significance of Head-Tilting in the Great Blue Heron. Nature 242:533-535.

1974. Colonial Nesting and Social Feeding as Strategies for Exploiting Food Resources in the Great Blue Heron (Ardea herodias). Behavior 51:99-134.

1978. Optimal Foraging: Decision Rules for Predators. Pages 25-53. in J. Krebs and N. Davies Editors. Behavioral Ecology: An Evolutionary Approach. Sinauer Associates, Sunderland, Mass. USA. 
Kushlan, James A. 1976. Feeding Behavior of North American Herons. The Auk 93:86-94.

. 1979. Feeding Ecology and Prey Selection in the White Ibis. Condor 81:376-389.

\section{bull 93 (2) 145-163.}

LaPorte, P. 1982. Organochlorine Residues and Eggshell

Measurements of Great Blue Heron Eggs from Quebec. Colonial Waterbirds 5:95-103.

McAloney, Keith. 1973. The Breeding Biology of the Great Blue Heron on Tobacco Island, Nova Scotia. Canadian Field Naturalist. 87-137-140.

Meterriecks, Andrew J. 1962. Diversity Typifies Heron Feeding. Nat. Hist. 71:48-59.

. 1960. Comparative Breeding Behavior of Four Species of North American Herons. Publ. Nutall. Ornithological Club 2, p1158.

Mock, Douglas W. 1976. Pair-Formation Displays of the Great Blue Heron. The Wilson Bull 88 (2):185-376.

Palmer, R. S., ed. 1962. Great blue heron. Pages 391-403 in R. S. Palmer, ed. Handbook of North American Birds. Vol. 1. Yale University Press, New Haven, Conn.

Pratt, Helen M. 1970. Breeding Biology of Great Blue Heron and Great Egrets in Central California. The Condor 72:407-416.

- 1974. Breeding of Great Blue Herons and Great Egrets at Audubon Canyon Ranch, California, 1972-1973. Western Birds, 5:127-136. 
Pratt, Helen M. and David W. Winkler. 1985. Clutch Size, Timing of Laying, and Reproductive Success in a Colony of Great Blue Herons and Great Egrets. The Auk 102:49-63.

Pyke, G. 1978. Optimal Foraging in Hummingbirds: Testing the Marginal Value Theorem. Am. Zoologist 18:739-752.

Recher, H.F. and J.A. Recher. 1972. The Foraging Behavior of the Reef Heron. EMU 72:85-90.

1969. The Comparative Foraging Efficiency of Adult and Juvenile Little Blue Herons (Florida caerulea). Anim. Behav. 17:320-322.

Richner, H. 1986. Winter Feeding Strategies of Individually Marked Herons. Animal Behav. 34:881-886.

Rudolph, S. 1982. Foraging Strategies of American Kestrals During Breeding. Ecology 63: 1268-1276.

Schoener, T. 1971. The Theory of Foraging Strategies. Ann. Rev. Ecol. Syst. 2:369-404.

Simpson, K and J. P. Kelsall. 1978. Capture and Banding of Adult Great Blue Herons at Pender Harbour, British Columbia. Proc. Colonial Waterbird Group. pp 71-78.

Smith, R.E. 1973. The Hyrography of Elkhorn Slough A Small California Coastal Embayment. October 1970 to February 1972. M.L.M.L. Tech Publ. 73-2:1-88.

Vermeer, Kees. 1969. Great Blue Heron Colonies in Alberta. The Canadian Field Naturalist. 83:237-242. 
Vermeer, Kees and Lincoln M. Reynolds. 1970. Organochlorine Residues in Aquatic Birds in the Canadian Prairie Provinces. Can. Field Nat. V84:117-130. [1972 Additonal Info. on Egg Shell Thickeness in Relation to DDE Concentration in Great Blue Heron's Eggs. Can Field-Nat. 86:384-385.]

Walmsley, J.G. 1975. The Development of a Breeding Population of Grey Heron (Ardea cinerea) in the Camarague La Terre et La Vie 29:89-99.

Werschkul, David, Ellen McMahon, Mary Leitschuh, Scott English, Charlotte Skibinski and George Williamson. Observations on the Repro. Ecology of the Great Blue Heron (Ardea herodias) in W. Oregon at the Murrelet 58:7-12.

Willard, David E. 1977. The Feeding Ecology and Behavior of Five Species of Herons in S.E. New Jersey. The Condor 79:462-470. 


\section{APPENDIX I}

A summary of Great Blue Heron behavior that is not covered in the main body of this paper provides a basis for an understanding and additional references on this species. There are several studies that detail breeding biology, and the factors affecting breeding success such as predation and human disturbances. Also, the colonial nesting of Great Blue Herons have inspired studies that reveal social aspects and benefits of this behavior such as increased foraging success.

The breeding biology of colonial nesting Great Blue Herons has been studied extensively by a number of researchers at many different locations (Pratt and Winkler 1985, Werschkul 1977, Henny and Bethers 1971, Vermeer 1969). Behavior was documented in an early study of a colony in Michigan (Cottrile and Cottrile 1958). Courtship typically involves pair bonding, presentation of nest material, erection of plumes and crest, clapping bills and mutual preening. The nest is described as a 
flat and flimsy platform constructed during the first year or a previous year's nest added to and repaired. Herons prefer nest sites well off the ground, in trees, although man made structures have been utilized. When trees are not available for nesting, herons will often nest in low bushes. Copulation occurs within two weeks of pair bonding and nest building.

Breeding season is progressively delayed as herons breed further north (Pratt 1970, Vermeer 1969). The season is variable for a specific area as well, with weather the determining factor (Pratt 1970). A study of a colony at Audubon Canyon Ranch, Marin County, California (Pratt and Winkler 1985) gives an estimate of the breeding season in Central California. The breeding season begins in mid February when nest sites become occupied. Copulation occurs in late February to early March. Egg laying proceeds throughout March and late clutches may occur as late as July. The incubation period between the last egg laid and the hatching of all eggs is approximately 28 days. After 7 to 8 weeks of age the young are fledged and begin taking short flights. Parental care continues for another few weeks, but by September 
the majority of fledglings have dispersed.

Breeding success is well documented by Pratt (1974). The overall mean clutch size at Audubon Canyon Ranch is roughly 3 eggs. The most productive size, meaning the clutch size leading to the highest fledgling success is 4 eggs, while the most frequent clutch size is 3 eggs. At higher latitudes there is an increase in the mean clutch size. This is an adaptive strategy of birds to insure breeding success in less favorable environmental conditions.

Vermeer (1969) estimated a mean clutch size of $\sim 5$ eggs ( $N$ = 11) in Alberta, Canada, while Mc Aloney (1973) estimated a mean clutch of $\sim 4$ eggs $(N=36)$ in Nova Scotia, Canada. The overall mean number of fledglings produced per nest also follows this latitudinal trend.

Further studies have involved the ecological factors affecting breeding success. Predation, human disturbances and the presence of organochloride residues are the major factors. Predation, by raccoons for example, can have devastating effects on colonial nesters (Pratt 1985). Other predators include Ravens, Great Horned Owls, Bald Eagles and Golden Eagles. Simon and 
Kelshall (1978) witnessed raids on nests by Ravens taking both eggs and young. They also found that Golden Eagles attack young, and at times even kill adults.

Grubb (1978) investigated the effects of increased noise levels on nesting birds and found a level of desensitivity by the herons. The sensitivity of nesting herons and wild flights by the entire colony are reported to cause reduced reproductive success (Bent 1926, Palmer 1976). Simpson and Kelshall (1978) compared the breeding behavior of an undisturbed versus a disturbed colony near a residential construction site. A greater number of active nests were abandoned (11) in disturbed than undisturbed colonies (1). Relocated nests and chick mortality also occurred more often at the disturbed colony. Interestingly, those adults that persevered in the presence of the disturbance were equally successful at raising young as those adults undisturbed. Pollutants adversely affect breeding success, especially organochlorides which accumulate in fish eating birds. Lower reproductive rates are directly associated with increased contamination. Both egg shell thickness and levels of DDE, 
dieldrin and PCB's within eggs have been analyzed in several locations in the United States and Canada (Vermeer and Reynolds 1970, Laporte 1982). Cooke et al (1976) provide additional information on pollution impact on Grey Herons, Ardea cinerea, in Great Britain.

A number of studies have addressed the reasons for colonial nesting. Nesting facilitation and anti predator mechanisms were suggested (Krebs 1973), as well as a strategy for exploiting food resources through "information centers" (Fisher 1954). The timing of departures from colonies by individuals and feeding behavior were recorded by Krebs (1973) and Pratt (1974). Krebs (1974) observed a "parasitic" association between herons leaving colonies and neighboring birds following them. Pratt (1974) observed that herons leaving the colony behaved independently. Tidal height and number of herons departing from a colony has also been correlated (Krebs 1974), however, and it is possible that apparent independence of behavior is often influenced by common external factors.

Further studies focus on feeding behaviors such as prey 
species taken, handling time of prey and ecological overlap among herons. Myerriecks (1961) reported the existence of specialized foraging techniques as the major factor allowing the variety of herons species to coexist. Hom (1983) concluded that the large size of the Great Blue Heron and its particular foraging technique are adaptive for capturing large fish. Co-occurring species such as Snowy Egret, Egretta thula, and the Great Egret, Casmerodius albus, are restricted to capturing smaller prey items; thus little overlap occurs between Great Blue Herons and Egret species. In general though, few long term studies on competitive relationships and feeding ecology have been completed. 